Part of the Journal of Research of the National Bureau of Standards

\title{
Thermal-Expansion Stresses in Reinforced Plastics ${ }^{1}$
}

\author{
By Philip S. Turner ${ }^{2}$
}

\begin{abstract}
Failure of adhesive bonds is attributed to boundary stress concentrations. An analysis of the causes of internal-stress concentrations in rigid adhesive layers leads to the conclusion that stress concentrations can be eliminated in many cases by matching the coefficients of thermal expansion of the component parts. A stress-equilibrium formula for calculating the thermal-expansion coefficients of mixtures involves the density, modulus of elasticity, coefficient of thermal expansion, and proportion by weight of the ingredients. Illustrations of the application of the derived formula include lead-antimony and beryllium-aluminum mixtures, phenol-formaldehyde resin and glass-fiber mixtures, and plastic plywoods. The thermal-expansion coefficients of a number of pure and reinforced plastics are reported. Bonds obtained when thermal coefficients are matched are stable over a wide temperature range.
\end{abstract}

\section{Introduction}

This report describes a method of compounding a plastic, or other mixture or compositions, to provide a material having a predetermined desired coefficient of thermal expansion. In the preparation of plastics heretofore it has been found practically impossible to produce a satisfactory bond between a plastic and a metal facing or other metal reinforcement. This is largely due to the difference in coefficients of expansion of the materials; the plastics have relatively high coefficients of expansion as compared with those of metals. Because of the differential expansion, forces created upon changes in temperatures have been such as to prevent a satisfactory bond being obtained between metals and plastics except where plastics of a flexible rubber-like, or gummy type are used. Even in the bonding of foils of tin, lead, aluminum, etc., to cardboard or paper for containers, only gummy or tacky plastics have been used.

The problem of obtaining bonds between plastics or other adhesives and various materials

\footnotetext{
1 The experimental work on this project was sponsored by and conducted with the financial assistance of the National Advisory Committee for Aeronautics, upon the recommendation of their Subcommittee on Wood and Plastics for Aircraft.

2 Deceased.
}

\section{Contents}

I. Introduction Page

II. Effect of various factors on bond strengths _.... 240

1. Thickness of materials bonded _......... 240

2. Thickness of adhesive ................ 240

3. Modulus of elasticity ................. 240

4. Moisture content_.................... 241

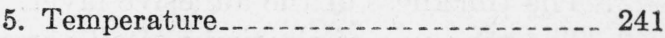

6. Thermal expansion $\ldots \ldots \ldots \ldots . . . . . . . . . . . .241$

7. Pressure of application ............... 241

III. Development of a formula for calculating coefficients of thermal expansion of mixtures _. . . . 241

IV. Applications to plastic compositions _.......... 243

1. Application to a mixture of polystyrene and aluminum oxide............... 243

2. Application to compositions for filling

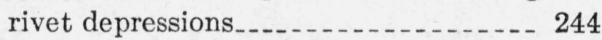

3. Application to mixtures of phenol-formaldehyde resin and glass fibers.......... 245

V. Determination of coefficients of thermal expansion of plastics......... 246

1. Factors affecting thermal-coefficient measurements of plastics ............ 247

2. Results of thermal-expansion measurements for plastics _............... 247

VI. Conclusions . . . . . . 
is considered as being substantially the same as that of removing or eliminating concentrated stresses at the boundaries. If internal-stress concentrations can be removed, the full strength of the adhesive can be developed to resist external loads.

Bonds produced by adhesives can be divided into two general classes: the rubbery or yielding bond and the rigid bond. In the first category are found most thermoplastic cements, rubber cements, and combinations of thin rubber layers and cements. Adhesives of this class have been found to provide durable bonds between dissimilar materials at moderate temperatures. The rigid or high modulus bond has generally been found unsatisfactory for such applications. A possible exception is found in the use of coldsetting cements of the phenol-formaldehyde and urea-formaldehyde types. The advantages of the first class over the second disappear at reduced temperatures where the adhesive loses its ability to eliminate stress concentrations by yielding with the dimensional changes of the materials bonded. The rigid bond is superior for many purposes to the yielding bond, if it can be ob- tained, because it produces a stronger and lessyielding product. For composite structural materials subjected to extreme temperature changes a stable rigid bond is imperative.

In attempting to bond various materials together, it has been found that materials having widely different coefficients of expansion cannot be bonded with any rigid cement available. Certain thermoplastic adhesives produce satisfactory bonds at ordinary temperatures, but fail at low temperatures when the bond becomes rigid and is no longer able to yield to changes in dimension of the materials bonded. Certain rubber cements fall into the classification of bonds which are soft enough to yield with changes in dimensions. These yielding bonds, however, do not produce the rigidity required for structural applications and fail at low temperatures for the same reason that rigid plastic bonds fail at ordinary temperatures; namely, difference in rates of expansion and contraction with changes in temperature.

These failures are caused by stresses resulting from differential expansion or contraction. These forces can be reduced by one or more of the following factors.

\section{Effect of Various Factors on Bond Strengths}

An analysis of the factors responsible for the production of stress concentrations in a rigid bond must include the following:

1. The thickness of the materials bonded.

2. The thickness of the adhesive layer.

3. The modulus of elasticity of all components.

4. Changes in dimensions with changes in moisture content for all materials.

5. Changes in temperature to be encountered in service.

6. Coefficients of linear thermal expansion of all materials.

7. Pressure of application.

\section{Thickness of Materials Bonded}

It is evident that if the thickness of the materials bonded approaches zero, stresses set up by any other combination of factors must also approach zero. Accordingly, it has been found possible to bond thin metal foils to other materials. A method of eliminating stresses by this means would, however, have very limited practical appli- cation. This stress-reducing factor is utilized in the production of mechanical mixtures of materials of microscopic size or in the form of fine filaments, which are incompatible on a larger scale.

\section{Thickness of Adhesive}

In bonding two pieces of the same material the stresses set up in the bond as the result of restrained dimensional changes in the bonding material would be proportional to the thickness of the bond. It has long been recognized that thin adhesive layers produce stronger bonds than thicker ones.

\section{Modulus of Elasticity}

If the modulus of elasticity of any one of two adjacent materials is zero, the stresses set up between them must be zero. This is essentially achieved by bonds which yield readily and offer little resistance to static loads whether produced internally or externally. 


\section{Moisture Content}

The problem of bonding materials having different dimensional stability with changes in relative humidity can be reduced, if not eliminated, if the surface of the combination is impervious to moisture. At the time of bonding or at the end of the bonding operation the material or materials sensitive to changes in humidity can be made to contain the normal amount of water present under average conditions. No completely satisfactory solution to this aspect of bonding has been found.

\section{Temperature}

Changes in temperature cannot be eliminated in any practical application. For cold-setting phenol-formaldehyde and urea-formaldehyde cements the effect of temperature changes is minimized by bonding at temperatures close to those encountered in service.

\section{Thermal Expansion}

From the standpoint of the thermal stresses produced, the problem of bonding two different materials becomes identical with the problem of bonding two pieces of the same material, provided the coefficients of thermal expansion of the two materials are the same. A further reduction in stresses can be achieved if the bonding agent has the same coefficient of thermal expansion as the materials bonded. A bond between materials having different coefficients of expansion would have to withstand the shear stresses produced by the differential expansion or contraction experienced within the range of temperatures encountered. Bonds can sometimes be maintained if the materials bonded are thin enough to permit the relief of stresses by bending or warping, either of which is undesirable. The bonding strength exhibited by a particular adhesive is the additional load which, added to the internal concentrated stresses, is sufficient to disrupt the material.
In some cases this additional load is zero and the materials are said not to bond.

\section{Pressure of Application}

When two materials are bonded together at high pressures, strains are produced at the bond when the pressure is released. This strain is proportional to the ratio of the moduli of elasticity of the two components. The lowest pressure feasible should be used to produce bonds with the lowest internal strains.

The logical conclusion to be drawn from the foregoing discussion is that stable rigid bonds are possible over a wide range of temperatures if the thermal-expansion coefficients of the component parts are matched. An example of the results to be expected is furnished by the combination of concrete and steel which individually have practically equal coefficients of thermal expansion and contraction. It is noted that certain proportions of cement, sand, and stone produce optimum results.

Various methods have been used in other fields to predetermine the thermal-expansion coefficients of mixtures, such as alloys, glasses, etc. Some of these methods appear to work satisfactorily in limited applications. Notable among these are weighted averages based on the thermal-expansion coefficients of the components and their proportions either by weight or by volume. These methods do not, however, give satisfactory results for plastic compositions.

It seems reasonable to expect that the coefficient of thermal expansion of a mixture is a function of the relative compressibilities, as well as the thermal expansion coefficients and the proportions of the components. In the following section a formula for the coefficient of thermal expansion for a mixture is obtained which, although not derived rigorously (according to the theory of elasticity), does take into account the relative compressibilities of the components.

\section{Development of a Formula for Calculating Coefficients of Thermal Expansion of Mixtures}

If it is considered that an internal stress system in a mixture is such that the stresses are nowhere sufficient to disrupt the material, the sum of the internal forces can be equated to zero and an expression for the thermal-expansion coefficient of the mixture is obtained. When small particles or fine filaments are incorporated into a mixture, the small dimensions appear to permit combinations 
of materials which would be incompatible on a larger scale.

The derivation of the resulting volume thermal coefficient of a mixture follows. The symbols used are:

$\alpha=$ coefficient of linear thermal expansion

$\beta=$ coefficient of cubical thermal expansion

$K=$ bulk modulus $=1 /$ bulk compressibility

$d=$ density

$P=$ fraction or percent by weight

$V=$ volume

$\Delta T=$ temperature difference

$S=$ stress

Subscripts $i$ and $r$ refer respectively to the property of the $i$ th component and of the resultant mixture.

If it is assumed that each component in the mixture is constrained to change dimensions with temperature changes at the same rate as the aggregate and that shear deformation is negligible, the stresses acting on the particles of the various components will be

$$
S_{i}=\left(\beta_{r}-\beta_{i}\right) \Delta T K_{i},
$$

as the stress is given by the product of volume strain and bulk modulus. The resultant of the forces acting on any cross section of the mixture must vanish. Therefore,

$$
S_{1} A_{1}+S_{2} A_{2}+\ldots+S_{n} A_{n}=0,
$$

where there are $n$ components and the $A$ 's refer to the parts of the cross-sectional area formed by the various components. However, in a homogeneous mixture the relative areas formed in the cross section by the different components are proportional to their relative volumes. Therefore, it follows from equation 2 that

$$
S_{1} V_{1}+S_{2} V_{2}+\ldots+S_{n} V_{n}=0 \text {. }
$$

Substitution for $S$ from equation 1 in equation 3 then yields

$$
\begin{aligned}
& \left(\beta_{r}-\beta_{1}\right) \Delta T V_{1} K_{1}+\left(\beta_{r}-\beta_{2}\right) \Delta T V_{2} K_{2}+\ldots+ \\
& \left(\beta_{r}-\beta_{n}\right) \Delta T V_{n} K_{n}=0 .
\end{aligned}
$$

As

$$
V_{1}+V_{2}+\ldots+V_{n}=V_{r}, V_{i}=\frac{P_{i} d_{r} V_{r}}{d_{i}}
$$

which can be substituted for $V$ in equation 4 . Also, as $\Delta T, d_{r}$, and $V_{r}$ are common factors, they can be eliminated from each term of the expression. Solving for $\beta_{r}$, the following expression is obtained:

$$
\beta_{r}=\frac{\frac{\beta_{1} P_{1} K_{1}}{d_{1}}+\frac{\beta_{2} P_{2} K_{2}}{d_{2}}+\cdots+\frac{\beta_{n} P_{n} K_{n}}{d_{n}}}{\frac{P_{1} K_{1}}{d_{1}}+\frac{P_{2} K_{2}}{d_{2}}+\cdots+\frac{P_{n} K_{n}}{d_{n}}}
$$

As the coefficient of linear thermal expansion is directly proportional to the cubical coefficient, $\alpha$ can be substituted wherever $\beta$ appears with the following

$$
\alpha_{r}=\frac{\frac{\alpha_{1} P_{1} K_{1}}{d_{1}}+\frac{\alpha_{2} P_{2} K_{2}}{d_{2}}+\cdots+\frac{\alpha_{n} P_{n} K_{n}}{d_{n}}}{\frac{P_{1} K_{1}}{d_{1}}+\frac{P_{2} K_{2}}{d_{2}}+\cdots+\frac{P_{n} K_{n}}{d_{n}}}
$$

It is apparent by inspection that equation 6 based on stress equilibrium reduces to a percentage by volume calculation if the ingredients have

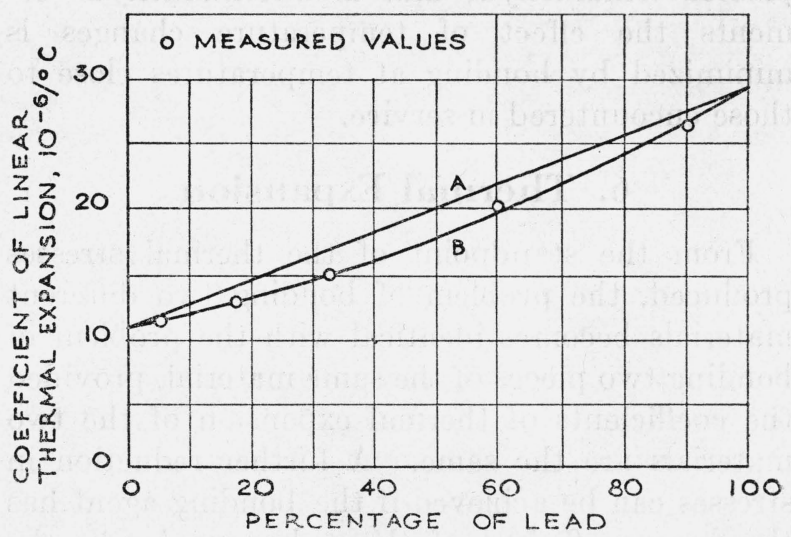

FIGURE 1.-Thermal-expansion coefficients of lead-antimony mixtures.

Curve $A$. Percentage by weight calculation.

Curve $B$. Percentage by volume or stress equilibrium calculation.

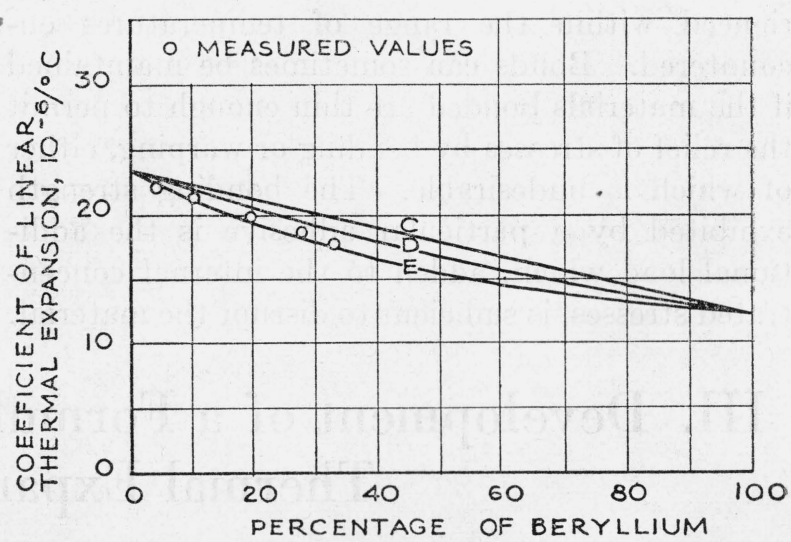

FugURE 2.-Thermal-expansion coefficients of berylliumaluminum alloys

Curve $C$. Percentage by weight calculation.

Curve $D$. Percentage by volume calculation.

Curve $E$. Stress equilibrium calculation. 
the same bulk moduli. If the ingredients have the same modulus to weight ratios, the calculation amounts to a percentage by weight interpolation.

Equation 6 has been verified with experimental values of several metallic mixtures. The thermalexpansion coefficients calculated according to equation 6 for several mixtures of lead and antimony and of beryllium ${ }^{3}$ and aluminum are compared with the measured values in figures 1 and 2 .

\section{Applications to Plastic Compositions}

It has been found that the size and shape of the filler particles in plastic mixtures have an effect on the resultant coefficient of expansion of the mixture. The equations derived do not take this phenomenon into consideration. Difficulty is also encountered because the moduli of some materials are not available. To solve these problems, equation 6 is modified by substituting an empirically determined constant $C$ for $K / d$ for each material. Constant $C$ is interpreted as proportional to the modulus-density ratio rather than being equal to it. The proportionality factor is dependent on the shape and size of the particles and on the distribution of the material in the matrix. It is assumed that the constant $C$ for each specific filler and each plastic material is independent of the other components of a mixture if the ingredients are evenly distributed. This modified equation has been used successfully in several investigations. The use of this technique and the effects of the shape and size of fillers have been described in another report. ${ }^{4}$

In studies of the physical properties of reinforced plastics it has been found that the strongest materials were produced by oriented fibers in thermosetting resins. The material fabricated in this manner is essentially non-isotropic in all of its properties and has different coefficients of expansion depending on the direction of the fibers in the test specimen. Materials having isotropic properties can be obtained by random distribution or by planned orientation. The solution for any property must take into consideration the orientation of the filler as well as the percentage composition.

For a mixture whose components have nearly

\footnotetext{
${ }^{3}$ Mixtures of $\mathrm{Be}$ and $\mathrm{Al}$ apparently form a mechanical mixture, but no value for the bulk modulus or bulk compressibility was available. From the thermal coefficient, $17.8 \times 10^{-6} /{ }^{\circ} \mathrm{C}$, of a known mixture containing 32.7 percent of $\mathrm{Be}$ and 66.3 percent of $\mathrm{Al}$, and with reported densities and thermal coefficients of the ingredients, the bulk modulus of Be was calculated from equation 6 to be $15.2 \times 10^{6} \mathrm{lb} /$ in $^{2}$. From this value the thermal coefficients of other mixtures of $\mathrm{Be}$ and $\mathrm{Al}$ were calculated with the results shown in figure 2 in comparison with the reported values.

${ }^{4}$ Philip S. Turner. Jewel Doran, and Frank W. Reinhart, Fairing compositions for aircraft surfaces. NACA Technical Note No. 958 (November 1944)
}

equal values of Poisson's ratio the bulk moduli are nearly proportional to the corresponding Young's moduli. For such mixtures Young's modulus may therefore be substituted for bulk modulus in equation 6 to yield the following expression for the thermal expansion coefficient of a mixture:

$$
\alpha_{r}=\frac{\frac{\alpha_{1} P_{1} E_{1}}{d_{1}}+\frac{\alpha_{2} P_{2} E_{2}}{d_{2}}+\ldots+\frac{\alpha_{n} P_{n} E_{n}}{d_{n}}}{\frac{P_{1} E_{1}}{d_{1}}+\frac{P_{2} E_{2}}{d_{2}}+\ldots+\frac{P_{n} E_{n}}{d_{n}}} .
$$

Thus, in many cases where the bulk moduli are not available, equation 7 may be used instead of equation 6 . The following experiments on a mixture of polystyrene and aluminum oxide illustrate the reasonably successful application of equation 7 .

\section{Application to a Mixture of Poly- styrene and Aluminum Oxide}

The applicability of the formula is illustrated by the behavior of brass inserts in a mixture of styrene resin with fused aluminum-oxide powder. Brass inserts in ordinary polystyrene cause the polystyrene to crack because of the different coefficients of thermal expansion. The coefficient of linear thermal expansion of polystyrene is approximately $70 \times 10^{-6} / \mathrm{deg} \mathrm{C}$, that of brass is approximately $17 \times 10^{-6} / \mathrm{deg} \mathrm{C}$.

Fused aluminum oxide was chosen for use in the mixture because it has a low coefficient of linear thermal expansion $\left(8.7 \times 10^{-6} / \mathrm{deg} C\right)$ and a high modulus of elasticity compared to its density. Its choice for use with polystyrene was also determined in part by its desirable electrical properties. There was no appreciable change in the excellent electrical resistance of polystrene when the aluminum-oxide filler was added. The data in table 1 for the coefficients of linear thermal expansion of mixtures of polystyrene and fused aluminum oxide, calculated according to the stress-equilibrium, formula show that approximately 90 percent of 
polystyrene and 10 percent of aluminum oxide would be required to match the coefficient of linear thermal expansion of brass. As the coefficient of the particular brass used was not accurately known, and as it was thought better to err on the low side, 11 percent of aluminum oxide was used.

TABLE 1.-Calculated coefficients of linear thermal expansion of mixtures of polystyrene and fused aluminum oxide

\begin{tabular}{|c|c|c|c|}
\hline \multicolumn{2}{|c|}{ Composition of mixture } & $\begin{array}{c}\text { Calculated coefficient of linear } \\
\text { thermal expansion }\end{array}$ \\
\hline $\begin{array}{c}\text { Fused alumi- } \\
\text { num oxide } \\
\left(\mathrm{A}_{2} \mathrm{O}_{3}\right)\end{array}$ & Polystyrene & $\begin{array}{c}\text { By stress equi- } \\
\text { librium formula } \\
\text { (equation 7) }\end{array}$ & $\begin{array}{c}\text { By rule of mix- } \\
\text { tures on per- } \\
\text { centage by vol- } \\
\text { ume basis }\end{array}$ \\
\hline$\%$ & $\%$ & $10^{-6 /{ }^{\circ} \mathrm{C}}$ & $10^{-6 /{ }^{\circ} \mathrm{C}}$ \\
100 & 0 & 8.7 & 8.7 \\
75 & 25 & 9.0 & 41.7 \\
50 & 50 & 9.6 & 56.3 \\
25 & 75 & 11.7 & 64.7 \\
20 & 80 & 12.5 & 65.9 \\
9.7 & 90.3 & 17 & 68.2 \\
5 & 95 & 23.2 & 69.1 \\
0 & 100 & 70 & 70 \\
\hline
\end{tabular}

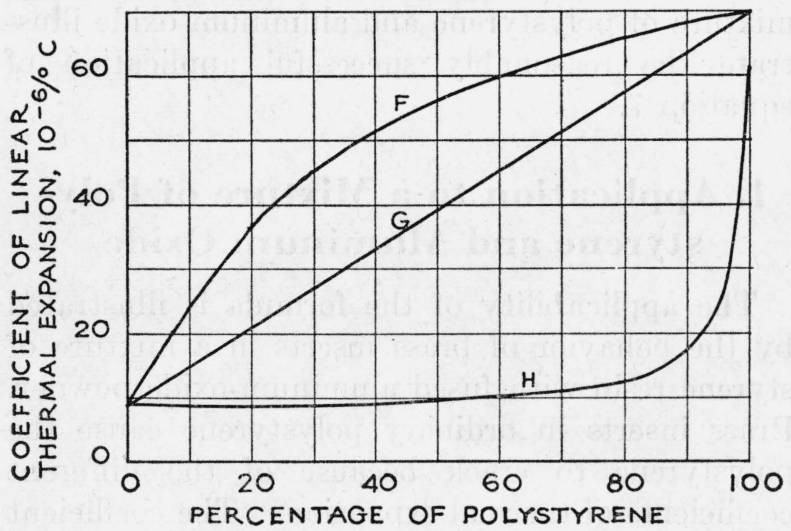

FIGURE 3.-Thermal-expansion coefficients of polystyrene and fused aluminum-oxide mixtures.

Curve $F$. Percentage by volume calculation.

Curve $G$. Percentage by weight calculation.

Curve $H$. Stress equilibrium calculation.

In figure 3, curve $F$ represents the values of the coefficient of linear thermal expansion of mixtures of polystyrene and fused aluminum oxide calculated on a percentage by volume basis; curve $G$, on a percentage by weight basis; and curve $H$, by the stress-equilibrium formula (equation 7). Although the thermal coefficient of a mixture of 89 percent of polystyrene and 11 percent of fused aluminum oxide has not been measured, pieces molded with brass inserts show a radical difference between the behavior of pure polystyrene and the filled material. Analysis with polarized light indicates that there are stresses in the pure polystyrene concentrated at the boundaries between the brass and polystyrene, and these are sufficient to rupture the polystyrene. With 11 percent of fused aluminum-oxide filler no such stress concentrations occur, and there is no evidence that the filled styrene has fractured. The brass was sufficiently well bonded to the polystyrene mixture to permit sawing and machining of the composite material.

The conventional methods of calculation would yield for this composition a value of $63 \times 10^{-6} / \mathrm{deg} \mathrm{C}$ for the coefficient of linear thermal expansion on a percentage by weight basis, which would indicate that the material should behave very nearly the same as the pure polystyrene. The behavior of the material, however, indicates that its coefficient is close to that of brass, which value was used to predetermine the composition by the use of the stress-equilibrium formula.

\section{Application to Compositions for Filling Rivet Depressions}

Rivet fillers for aluminum, used to cover depressions caused by riveting, have been tested by exposure to Washington weather for 1 year. An enigma developed when it was found that the composition having the best general weathering characteristics did not stand up the best in this application. The calculated values for coefficients of linear thermal expansion of the various compositions are as follows:

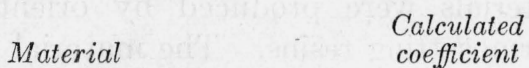

Cellulose nitrate +25 percent of aluminum pigment .............. $44.2 \times 10^{-6} / \mathrm{deg} \mathrm{C}$ Cellulose acetate butyrate +25 percent

of aluminum pigment........... $45.2 \times 10^{-6} / \mathrm{deg} \mathrm{C}$ Vinylite AYAF + 30 percent of aluminum pigment........ $30.6 \times 10^{-6} / \mathrm{deg} \mathrm{C}$

As the coefficient of linear thermal expansion of aluminum is $24 \times 10^{-6} / \mathrm{deg} \mathrm{C}$, the results are easily explained on the basis that composition 3, which happened to come closest to the coefficient of aluminum, gave the best bond.

Inasmuch as the lowest coefficient obtainable with aluminum pigment is $24 \times 10^{-6} / \mathrm{deg} \mathrm{C}$ for 100-percent pigment, it becomes necessary to add another ingredient with a coefficient below aluminum to the plastic in order to obtain matched thermal coefficients. The following proportions 
were calculated for cellulose-plastic compositions to reasonably match aluminum:

Percent

Cellulose nitrate or cellulose acetate butyrate_.... 66

Aluminum pigment ........... 20

Fused aluminum oxide . . . . . . . . . . . . . . . . 14

Similarly, the following proportions were calculated for a vinyl acetate resin composition to match its coefficient of linear thermal expansion with that of aluminum:

$\begin{array}{lr} & \text { Percent } \\ \text { Vinylite AYAF resin } & 74.6\end{array}$

Aluminum pigment._... 20.0

Fused aluminum oxide.

\section{Application to mixtures of phenol- formaldehyde Resin and Glass Fibers}

Approximate values for the properties of glass and phenol-formaldehyde resin required for use in the stress-equilibrium formula are as follows:

\section{Young's modulus of elasticity:}

For glass . . . . .

For phenolic resin _............. $1 \times 10^{6} \mathrm{lb} / \mathrm{in}^{2}$.

Coefficient of linear thermal expansion:

For glass_... _...

For phenolic resin . . . . .

Density $(\mathrm{g} / \mathrm{ml})$ :

For glass .

For phenolic resin

1. 30

In order to simplify the calculation of the coefficients of linear thermal expansion of mixtures of these materials, equation 7 can be written in a form consolidating the physical constants:

$$
\alpha_{\tau}=\frac{a_{1} P_{1}+a_{2} P_{2} \ldots+a_{n} P_{n}}{b_{1} P_{1}+b_{2} P_{2} \ldots+b_{n} P_{n}}
$$

in which $a$ and $b$ are constants for specific materials for a specific temperature range. The approximate values for these constants for the phenolformaldehyde resin and glass calculated from the physical constants listed above are

\begin{tabular}{ccc} 
& Glass & Phenol-formaldehyde resin \\
\hline$b \times 10^{6}$ & 29.1 & 45.4 \\
& & 0.77
\end{tabular}

In figure 4, curve I represents a percentage by weight interpolation for the glass-resin mixtures; curve $J$ is calculated by the stress-equilibrium formula. Measured values of the coefficients of linear thermal expansion of two compositions shown in table 2 are plotted according to the percentage of the resin in the mixture. These samples contained approximately 4 percent of starch,

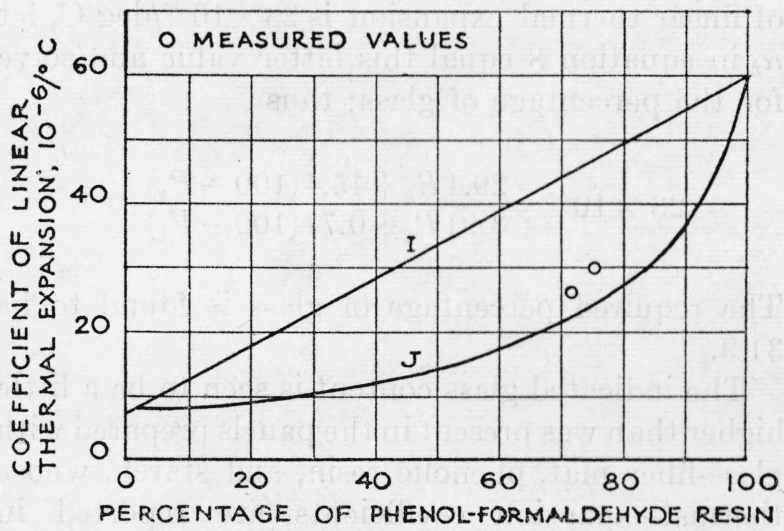

FIGURE 4.-Thermal-expansion coefficients of phenolformaldehyde resin and glass-fiber mixtures containing approximately 4 percent of starch.

Curve I. Percentage by weight calculation (not including starch). Curve J. Stress equilibrium calculation (not including starch).

which was neglected in calculating curve $J$. The theoretical coefficients for the compositions containing starch were not calculated because the required physical constants are not known. The experimental points fall much closer to the curve $J$ calculated by the formula than to curve $I$. The curve on a percentage by weight basis would be similar to curve $F$ in figure 3 and would be still further from predicting the actual result.

TABLE 2.-Coefficients of linear thermal expansion of mixtures of glass fibers, phenolic resin, and starch

\begin{tabular}{|c|c|c|c|c|}
\hline \multicolumn{3}{|c|}{ Composition of mixture } & \multicolumn{2}{|c|}{$\begin{array}{c}\text { Coefficient of linear thermal } \\
\text { expansion }\end{array}$} \\
\hline $\begin{array}{l}\text { Glass } \\
\text { flber }\end{array}$ & $\begin{array}{c}\text { Phenol- } \\
\text { formaldehyde } \\
\text { resin } \\
\text { (Bakelite } \\
\text { XC-11749) }\end{array}$ & Starch & $\begin{array}{l}\text { Calculated } \\
\text { by stress } \\
\text { equilibrium } \\
\text { formula } \\
\text { (equation } 7 \text { ) }\end{array}$ & Measured \\
\hline$\%$ & $\%$ & $\%$ & $10^{-6} / \operatorname{deg} C$ & $10^{-8} / \operatorname{deg} C$ \\
\hline 100 & 0 & & 7.44 & \\
\hline 50 & 50 & & 14.2 & . n \\
\hline 25.2 & 70.8 & 4 & & 26.0 \\
\hline 25 & 75 & & 23.6 & (1) \\
\hline 22.2 & 73.8 & 4 & - n & 29.9 \\
\hline 10 & 90 & & 37.4 & $-\ldots$ \\
\hline 0 & 100 & & 60 & (n) \\
\hline
\end{tabular}

The addition of metal faces to reinforced plastics may be desired in order to take advantage of the high-modulus properties of metals, as in an I-beam, or to obtain a facing impermeable to moisture. To do this effectively it would be necessary to have matched thermal-expansion coefficients in order to insure satisfactory bonds. To calculate the mixture of glass fiber and phenolic resin required to match aluminum alloy $24 S$, whose coefficient 
of linear thermal expansion is $23 \times 10^{-6} / \mathrm{deg} \mathrm{C}$, let $\alpha_{r}$ in equation 8 equal this latter value and solve for the percentage of glass; thus

$$
23 \times 10^{-6}=\frac{29.1 P_{g}+45.4\left(100-P_{g}\right)}{3.91 P_{g}+0.77\left(100-P_{g}\right)} 10^{-6} .
$$

The required percentage of glass is found to be 31.3 .

The indicated glass content is seen to be a little higher than was present in the panels prepared with glass-fiber mat, phenolic resin, and starch, whose thermal-expansion coefficients are reported in table 4. These panels were fabricated between aluminum-alloy-24S faces. It was found possible to remove the metal face without seriously damaging it or the core material. The metal faces could not be removed from several other panels, having compositions closer to that calculated, without tearing the metal, shearing the metal at the bond, or rupturing the core.

The starch was added to these compositions in order to absorb the water in the ingredients or released by the resin during curing. It has been found difficult or impossible to produce plastic compositions with this phenolic-thermosetting resin at low pressures unless some water-absorbent material is present. Some of these glass-fiber panels were bonded at pressures as low as 50 $\mathrm{lb} / \mathrm{in}^{2}$.

\section{Determination of Coefficients of Thermal Expansion of Plastics}

In the early stages of the investigation an estimate of the coefficient of thermal expansion of the resin-bonded materials was obtained by the following method. Composite strips of one layer of metal and one of a fibrous material impregnated with the resin in varying proportions was pressed flat and cured at $150^{\circ} \mathrm{C}$. The strips were then permitted to cool to room temperature. If the composite strip remained straight when cooled, it was considered that the thermal expansion of the plastic composition matched the metal. As the investigation proceeded, quantitative data for the coefficients of linear expansion of the resins were required.

The equipment used for this purpose consisted of two telescoping fused-quartz tubes, the inner tube being shorter than the outer and resting on the specimen. The expansion was measured by a dial gage, graduated to 0.0001 in., and fastened to the outer quartz tube with the measuring foot resting on the inner quartz tube, which in turn rested on the specimen. The temperature of the specimen was varied by immersing the quartz tubes containing the specimen in a water or an oil bath, heated with a hot plate, so that the rate of temperature rise of the bath was approximately $1 \mathrm{deg} \mathrm{C}$ per minute. The temperature of the specimen was measured by means of a potentiometer connected with a copper-constantan thermocouple, which was attached to the center of the specimen. Simultaneous measurements of temperature and extension were obtained by setting the potentiometer at predetermined points and recording the extension when no deflection was produced by opening or closing the circuit. The coefficient of linear expansion of the specimen was calculated from the temperature-extension curves. The results thus obtained were corrected for the expansion of the fused-quartz tubes by adding the coefficient of linear thermal expansion of fused quartz, $0.5 \times 10^{-6} / \mathrm{deg} \mathrm{C}$. Although this relatively rapid method does not insure a uniform temperature throughout the specimen, it presents a better picture of the changes taking place in the specimen which might be masked by changes in water content and by plastic flow at elevated temperatures, both of which would appreciably affect the results if the time of heating the specimen was prolonged. The stress on the specimen applied by the inner quartz tube and the micrometer foot did not exceed $10 \mathrm{lb} /$ in. $^{2}$

The specimen used for thermal-coefficient measurements was a bar $6 \frac{1}{2}$ to $7 \frac{1}{2}$ in. long and about $1 / 2$ in. wide. The thickness was that of the sheet from which the specimen was cut. Specimens for determination of the properties of both pure phenolic resin (Durez 120) and compositions of this resin containing filler were molded in the laboratory at $150^{\circ} \mathrm{C}$ and $1,000 \mathrm{lb} /$ in. $^{2}$ pressure. The length of the specimen was measured at room temperature to the nearest $0.01 \mathrm{in}$. with a steel scale. The specimens were rounded on the ends in order to obtain definite contact between the specimen and the apparatus over a small area. The position of the specimen with respect to the quartz tubes was maintained by washers near the ends of the spec- 
imen which came in contact with the sides of the tubes but offered no appreciable resistance to vertical motion of the specimen.

Measurements of the coefficient of linear expansion of an alloy using the method described above are compared in table 3 with precision measurements on a duplicate sample. The results are not strictly comparable since the coefficient of linear expansion of the sample changes slightly with the heat treatment occurring during measurement. Because the time required to make the measurements differs in the two methods, the amount of annealing that has occurred between measurements is different. The results, however, are essentially the same and indicate that the method employed for the experimental work described in this paper is quite reliable.

TABLE 3.-Comparison of precision method and rapid method of measuring coefficients of linear thermal expansion

\begin{tabular}{|c|c|c|c|c|}
\hline \multirow{3}{*}{$\begin{array}{c}\text { Temperature } \\
\text { range }\end{array}$} & \multicolumn{4}{|c|}{ Average coefficients of linear thermal expansion } \\
\hline & \multicolumn{2}{|c|}{ Precision method a } & \multicolumn{2}{|c|}{ Rapid method } \\
\hline & First test & Repeat test & First test & Repeat test \\
\hline${ }^{\circ} \mathrm{C}$ & $10^{-6} /$ deg. $C$ & $10^{-6} /$ deg. $C$ & $10^{-8} / \mathrm{deg} . C$ & $10^{-6} /$ deg. $C$ \\
\hline 20 to 60 & 17.7 & 17.8 & 17.5 & 17.2 \\
\hline 60 to 100 & 18.6 & 18.3 & 17.9 & 18.7 \\
\hline 100 to 150 & 18.3 & 18.5 & 18.4 & 19.0 \\
\hline $15 \mathrm{C}$ to 200 & -... & 18.7 & 19.0 & 19.3 \\
\hline 20 to 100 & 18.1 & 18.0 & 17.7 & 17.9 \\
\hline 20 to 150 & 18.2 & 18.2 & 18.0 & 18.3 \\
\hline 20 to 200 & -... & 18.4 & 18.3 & 18.6 \\
\hline
\end{tabular}

a Data supplied by Division II-6. The cooperation of P. Hidnert in supplying this information and other data represented graphically in figures 1 and 2 is gratefully acknowledged.

\section{Factors Affecting Thermal-Coef- ficient Measurements of Plastics}

Before considering the actual measurements, some of the factors peculiarly affecting the thermal expansion and related properties of plastics should be discussed. Organic plastic compositions, or water-absorbent materials, in general, in addition to the basic constituents, contain a certain amount of water which apparently acts the same as an additional solid in the composition. A great deal of the variation in the reported values for the linear thermal expansion of wood is undoubtedly related to differences in the water content of the wood at the time of testing. In order to minimize such effects, all specimens tested in this investigation were initially conditioned at $25^{\circ} \mathrm{C}$ and 50-percent relative humidity.

The modulus of plastics varies considerably with change in temperature, particularly near the softening point. The range of temperature to which the reported values apply was chosen in each case to avoid large changes in water content and to avoid softening points. Each of these effects is indicated by bréaks in temperatureextension and extension-time curves. Near the softening point of pure plastics the molding strains are relieved and dimensional changes occur which depend on the method of manufacture. These changes correspond to the dimensional changes encountered on aging. Reinforced or laminated materials also show changes in dimensions involving the relief of the thermal stresses set up by the differential coefficients of expansion of the resin and reinforcing medium. Prolonged heating at elevated temperatures causes shrinkage by the removal of water from the mixture. The relief of molding stresses seems to be permanent; the removal of water reversible.

\section{Results of Thermal-Expansion Measurements for Plastics}

Representative measurements of thermal-expansion coefficients of plastic materials for various temperature ranges are presented in table 4 . A typical thermal-expansion curve for pure molded phenolic resin is shown in figure 5 .

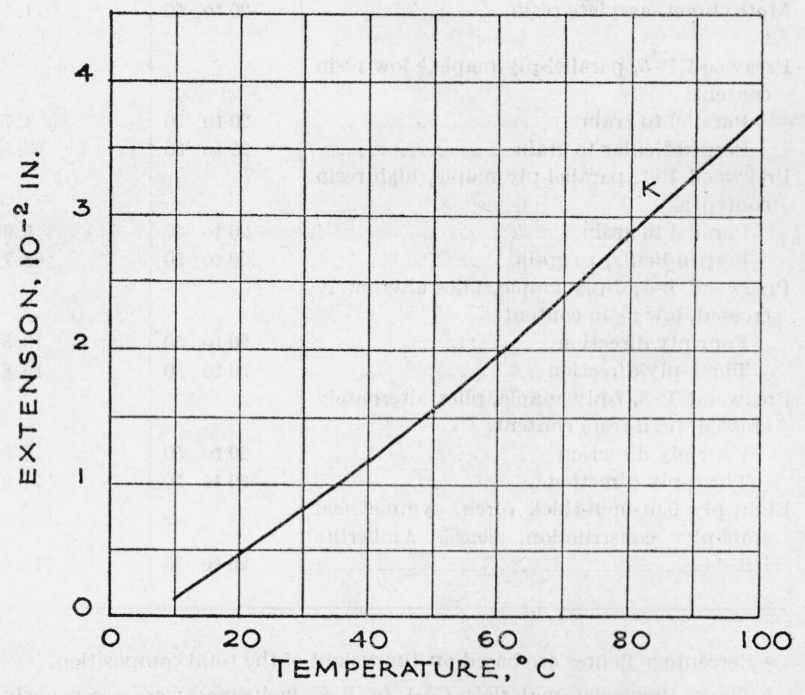

FIGURE 5.-Thermal-expansion curve for pure molded phenolic resin, Durez 120.

(Original length of specimen at room temperature: 7.05 in.). 
TABLE 4-Measured coefficients of linear thermal expansion for various plastics

\begin{tabular}{|c|c|c|}
\hline Material a & Range & $\begin{array}{l}\text { Linear } \\
\text { thermal- } \\
\text { expansion } \\
\text { coefficient }\end{array}$ \\
\hline Pure phenolic resin (Durez No. 120) & $\begin{array}{l}{ }^{\circ} C \\
20 \text { to } 100 \\
20 \text { to } 50 \\
20 \text { to } 30\end{array}$ & $\begin{array}{r}10^{-8} /{ }^{\circ} C \\
58.5 \text { to } 58.9 \\
49.7 \\
50.2\end{array}$ \\
\hline $\begin{array}{l}\text { Durez No. } 120,10 \% \text { Micronex (channel-type } \\
\text { carbon black). } \\
\text { Durez No. } 120,41 \% \text { reagent-quality aluminum }\end{array}$ & $\begin{array}{l}20 \text { to } 100 \\
20 \text { to } 100\end{array}$ & $\begin{array}{r}45.7 \text { to } 47.4 \\
44.9\end{array}$ \\
\hline oxide & $\begin{array}{l}20 \text { to } 50 \\
20 \text { to } 100\end{array}$ & $\begin{array}{l}34.7 \\
62.8\end{array}$ \\
\hline Durez No. $120,10 \%$ lignin resin (first heating)- & $\begin{array}{l}53 \text { to } 100 \\
20 \text { to } 53\end{array}$ & $\begin{array}{l}78.8 \\
47.9\end{array}$ \\
\hline ing) & $\begin{array}{l}20 \text { to } 100 \\
20 \text { to } 100\end{array}$ & $\begin{array}{l}54.7 \\
54.1\end{array}$ \\
\hline Durez No. $120,10 \%$ lignin resin (third heating) - & $\begin{array}{l}20 \text { to } 53 \\
53 \text { to } 100\end{array}$ & $\begin{array}{l}47.2 \\
59.9\end{array}$ \\
\hline $\begin{array}{l}\text { Durez No. } 120,10 \% \text { walnut-shell-flour filler } \\
\text { (first heating) }\end{array}$ & $\begin{array}{l}20 \text { to } 100 \\
49 \text { to } 100 \\
20 \text { to } 49 \\
20 \text { to } 100\end{array}$ & $\begin{array}{l}59.2 \\
68.0 \\
43.8 \\
54.1\end{array}$ \\
\hline $\begin{array}{l}\text { Durez No. } 120,10 \% \text { walnut-shell-flour filler } \\
\text { (second heating). }\end{array}$ & $\begin{array}{l}49 \text { to } 100 \\
20 \text { to } 49\end{array}$ & $\begin{array}{l}58.8 \\
45.7\end{array}$ \\
\hline $\begin{array}{l}\text { Glass Mat } 25 \% \text {, Bakelite XC-11749 phenolic } \\
\text { resin } 71 \% \text {, starch } 4 \% \text { : }\end{array}$ & & \\
\hline $\begin{array}{l}\text { First heating } \\
\text { Third heating }\end{array}$ & $\begin{array}{l}20 \text { to } 65 \\
20 \text { to } 65\end{array}$ & $\begin{array}{l}29.9 \\
29.3\end{array}$ \\
\hline Glass Mat 28\%, Bakelite XC-11749 68\%, starch & 20 to 70 & 26.0 \\
\hline $\begin{array}{l}\text { Glass Cloth } 44 \% \text {, Durez No. } 12039 \% \text {, starch } \\
17 \%\end{array}$ & 20 to 70 & 17.8 \\
\hline $\begin{array}{l}\text { Columbia resin No. } 39 \text { : } \\
\text { First heating }\end{array}$ & 10 to 50 & 103.3 \\
\hline Second heating..... & $\begin{array}{l}20 \text { to } 100 \\
20 \text { to } 50\end{array}$ & $\begin{array}{l}124.7 \\
105.8\end{array}$ \\
\hline Methyl-methacrylate resin & 20 to 50 & 71.5 \\
\hline $\begin{array}{l}\text { Pregwood P-5, parallel-ply maple, b low resin } \\
\text { content: }\end{array}$ & & \\
\hline Parallel to grain & 20 to 50 & 4. 7 \\
\hline Perpendicular to grain & 20 to 50 & 63.5 \\
\hline $\begin{array}{l}\text { Pregwood P-1, parallel-ply maple, high resin } \\
\text { content: }\end{array}$ & & \\
\hline Parallel to grain & 20 to 50 & 5.9 \\
\hline Perpendicular to grain & 20 to 50 & 68.7 \\
\hline $\begin{array}{l}\text { Pregwood P-7, 7-ply maple, plies alternately } \\
\text { crossed, low resin content: }\end{array}$ & & r \\
\hline Four-ply direction & 20 to 50 & 13.5 \\
\hline Three-ply direction & 20 to 50 & 19.8 \\
\hline $\begin{array}{l}\text { Pregwood P-3, 7-ply maple, plies alternately } \\
\text { crossed, high resin content: }\end{array}$ & & \\
\hline Four-ply direction & 20 to 50 & 16. 7 \\
\hline Three-ply direction & 20 to 50 & 21.0 \\
\hline $\begin{array}{l}\text { Eight-ply } 0.01 \text {-inch-thick birch, symmetrical } \\
\text { cross-ply construction, } 39.5 \% \text { Amberlite } \\
\text { PR-14 }\end{array}$ & 20 to 30 & 15.4 \\
\hline
\end{tabular}

- Percentage figures are based on the weight of the total composition.

b These Pregwood materials ( $\mathrm{P}-1$ to $\mathrm{P}-8$, inclusive) were erroneously reported to have been prepared with birch veneers in the NACA advance restricted report of July 1941, entitled "Properties of Reinforced Plastics and Plastic Plywoods."
Carbon black is frequently added to plastic compositions as a filler. It is interesting therefore to note that the addition of 10 percent of a channel type of carbon black to phenol-formaldehyde resin reduced the thermal coefficient of the mixture approximately 20 percent (see table 4). From published values for the density and thermal- expansion coefficient of carbon black, together with the measured properties of the pure phenolic resin, a value for the bulk modulus of carbon black was calculated to be approximately $3 \times 10^{6} \mathrm{lb} / \mathrm{in}^{2}$.

Lignin resin is used in a number of applications in conjunction with phenolic resins. Here it is treated as a filler. Two effects are to be noted: first, that the product does not become stable until it has been heated a considerable length of time beyond the time required to cure the phenolic resin; and second, that the lignin initially increases the coefficient of the mixture but after heating finally decreases it by a small amount.

The effect of the walnut-shell flour is similar to that of the lignin resin. The manufacturers of this material state that it contains a large proportion of lignin. One of the uses of this material is as an extender for plywood adhesives.

The behavior of filled phenol-formaldehyde resin containing 25 percent of glass fiber, 71 percent of phenolic resin, and 4 percent of starch, is illustrated by the curves for mixtures of glass fibers and phenolic resin shown in figure 6 . Curves $L$ and $O$ are for pure phenol-formaldehyde resin and glass fibers, respectively. Curve $N$ was obtained on the first heating cycle. The form of the curve above $70^{\circ} \mathrm{C}$ is affected by plastic flow, relief of molding strains, and further curing of the resin. The weight of the inner fused-quartz tube and the pressure of the micrometer foot contribute some of the force producing plastic flow. The shrinkage indicated at $100^{\circ} \mathrm{C}$ on curve $N$ took place over a period of 5 hours, during which time the temperature was maintained constant. The rate of shrinkage was initially rapid but reached a steady value after about 4 hours. After cooling the sample slowly and then reheating to $100^{\circ} \mathrm{C}$ the same steady rate of shrinkage was resumed for 4 additional hours, after which the specimen was slowly cooled to room temperature. The total shrinkage amounted to 0.5 percent. Curve $M$ of figure 6 is the thermal-expansion curve for this annealed specimen.

The transparent materials for which data are given in table 4 have been used or proposed for 


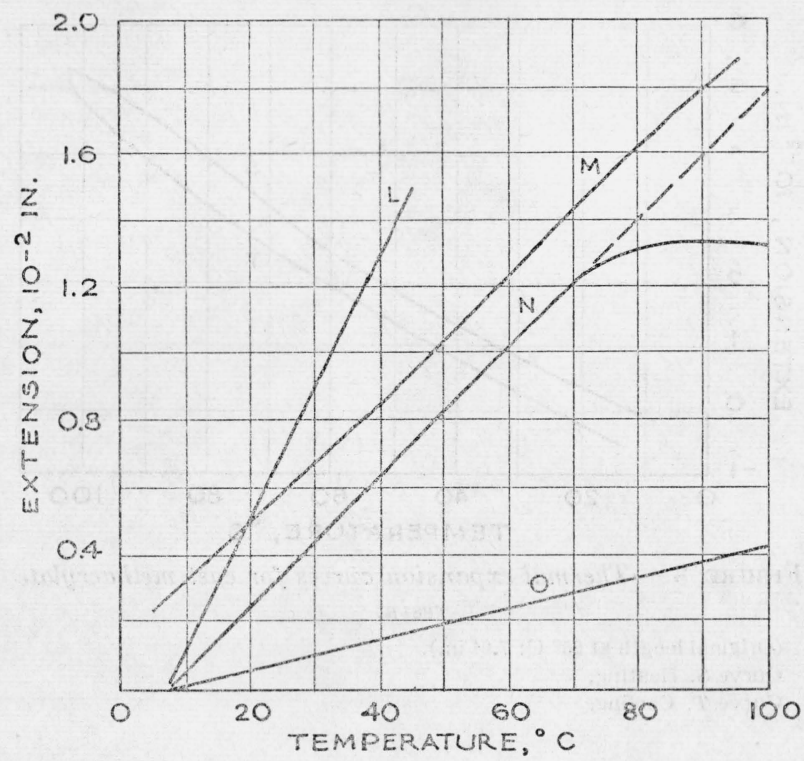

Figure 6.-Thermal-expansion curves for phenolic resin and glass fiber mixtures.

(Original length at $25^{\circ} \mathrm{C}: 6.57$ in.; final length at $25^{\circ} \mathrm{C}: 6.54 \mathrm{in}$.).

Curve $L$. Pure phenolic resin.

Curve $M$. Filled phenolic, third heating.

Curve $N$. Filled phenolic, first heating.

Curve $O$. Glass mat (manufacturer's data).

use as airplane windshields. The temperatureextension curves in each case varied from a smooth curve on the first heating cycle between $50^{\circ}$ and $100^{\circ} \mathrm{C}$. The curve for the Columbia Resin 39 sample (fig. 7 , curve $P$ ) showed a decrease in expansion in this range followed by a resumption of the upward trend. No such break occurred in the cooling curve (fig. 7, curve Q) or in the curve obtained when the sample was heated a second time (fig. 7, curve $R$ ), although the tem-

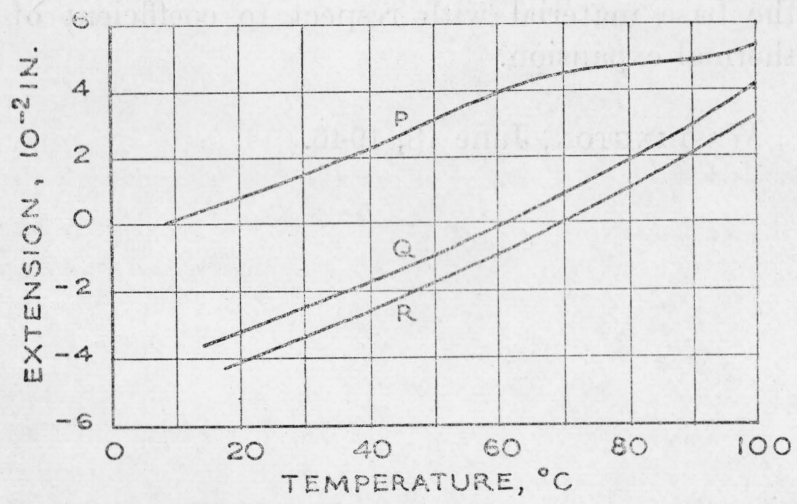

Frgure 7.-Thermal-expansion curves for Columbia Resin No. 39.

(Original length at room temperature: $7.48 \mathrm{in.}$ ).

Curve $P$. First heating.

Curve $Q$. First cooling.

Curve $R$. Second heating. perature was raised above $110^{\circ} \mathrm{C}$. The sample was permanently shortened during the first heating to the extent of 0.5 percent. The specimen at the same time increased in thickness. The curve for methyl-methacrylate resin (fig. 8, curve $S$ ) for the range $50^{\circ}$ to $100^{\circ} \mathrm{C}$ showed an increase in expansion followed by a decrease. Again the break did not occur in the cooling curve (fig. 8, curve $T$ ). The changes were too small to be measured significantly with a steel scale, so a check was run on smaller specimens that were heated in an oven at $80^{\circ} \mathrm{C}$ for 18 hours. The indicated change was verified by an increase in dimensions in the plane of the sheet and a decrease in thickness. This is in agreement with observed dimensional changes on aging. Methylmethacrylate resin is one of the best available materials from the standpoint of freedom from crazing, unless subjected to strain, and dimensional stability. The surfaces of both materials appeared to be unaffected by the treatment.

TABLE 5.-Coefficients of linear thermal expansion and moduli of elasicity of Pregwoods

\begin{tabular}{|c|c|c|c|c|}
\hline \multirow[b]{2}{*}{ Material } & \multicolumn{2}{|c|}{ Measured values a } & \multicolumn{2}{|c|}{ Calculated values } \\
\hline & $\begin{array}{l}\text { Modulus } \\
\text { of elastic- } \\
\text { ity in } \\
\text { tension }\end{array}$ & $\begin{array}{c}\text { Coeffi- } \\
\text { cient of } \\
\text { linear } \\
\text { thermal } \\
\text { expansion } \\
\text { for the } \\
\text { range } 20^{\circ} \\
\text { to } 50^{\circ} \mathrm{C}\end{array}$ & $\begin{array}{l}\text { Modulus } \\
\text { of elastic- } \\
\text { city in } \\
\text { tension }\end{array}$ & $\begin{array}{l}\text { Coeffi- } \\
\text { cient of } \\
\text { linear } \\
\text { thermal } \\
\text { expansion } \\
\text { for the } \\
\text { range } 20^{\circ} \\
\text { to } 50^{\circ} \mathrm{C}\end{array}$ \\
\hline
\end{tabular}

FigH RESIN CONTENT. PARALLEL-PLy MATERIAL (P-1)

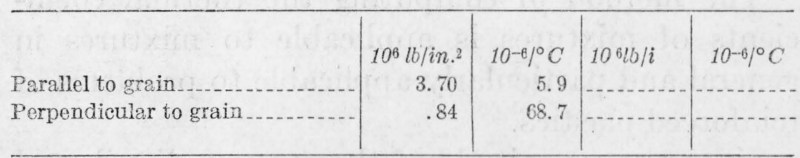

High RESIN CONTENT. CROSS-Ply MATERIAL, SEVEN PLy (P-3)

\begin{tabular}{l|l|l|l|l}
\hline Parallel to three-ply direction..- & 2.04 & 21.0 & 2.07 & 20.5 \\
Parallel to four-ply direction... & 2.29 & 16.7 & 2.47 & 15.0 \\
\hline
\end{tabular}

LOW RESIN CONTENIS, PARALLEL-PLY MATERIAL (P-5)

\begin{tabular}{l|r|r|r}
\hline Parallel to grain & 3.97 & 4.7 & \\
Perpendicular to grain & .68 & 63.5 & $\ldots \ldots \ldots \ldots$ \\
\hline
\end{tabular}

LOW RESIN CONTEND. CROSS-PLY MATERIAL, SEVEN PLY (P-7)

\begin{tabular}{l|l|l|l|l}
\hline & & & & \\
Parallel to three-ply direction.-- & 2.17 & 19.8 & 2.09 & 15.6 \\
Parallel to four-ply direction -..-- & 2.52 & 13.5 & 2.56 & 11.4 \\
\hline
\end{tabular}

a The values given for the coefficient of linear thermal expansion are those obtained on the first heating cycle. 
The Pregwood samples listed in table 4 were submitted by the Formica Insulation Co. and were cut from the same sheets as the test specimens reported upon in NACA Advance Restricted Report of July 1941, entitled "Properties of Reinforced Plastics and Plastic Plywoods." The modulus data reported at that time for parallelply material may be used with the measured thermal coefficients to calculate the thermal coefficients of the cross-ply material. The modulus of the cross-ply material may also be calculated as a composite column using the data for the parallel-ply materials. It is assumed, perhaps erroneously, that the "high" and "low" resin designations indicate definite resin contents. The calculated and observed values for the several properties are shown in table 5.

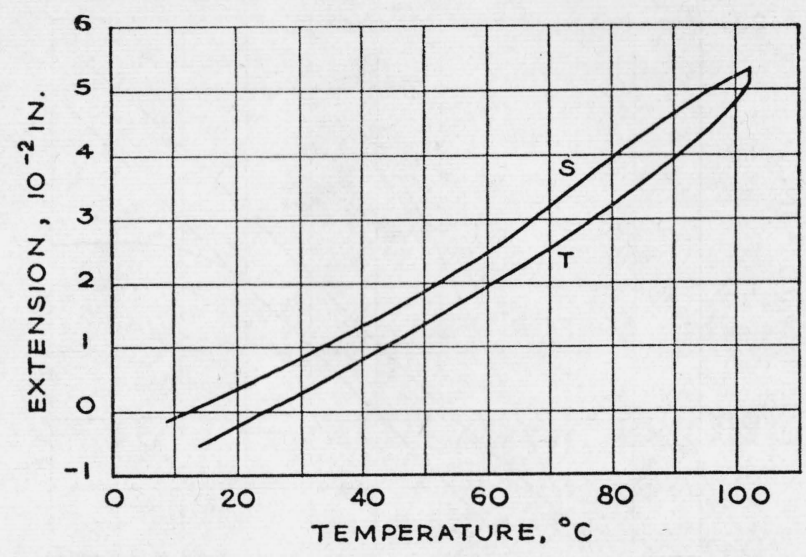

FIGURE 8.-Thermal-expansion curves for cast methacrylate resin.

(Original length at $25^{\circ} \mathrm{C}: 7.04$ in.).

Curve $S$. Heating.

Curve $T$. Cooling.

\section{Conclusions}

The implications of the concept and methods of analysis touched briefly in the preceding pages are too numerous to be adequately treated in so short a space. Special applications have been mentioned throughout the paper. Some general conclusions are presented in the following paragraphs.

Stable bonds are possible between large sections if the thermal coefficients of the component parts are matched. The bond under such conditions is not seriously affected by extreme temperature changes.

The method of computing the thermal coefficients of mixtures is applicable to mixtures in general and particularly applicable to problems of reinforced plastics.

Since the magnitude of the stresses distributed throughout the mixture is proportional to the size of the elements, the ultimate strength of the material and its fatigue limits should be raised by reducing particle size. Specifically, the strength of plywood should be increased by the use of thin veneers. At the temperature of fabrication the effect of particle size should reach a minimum.

It should be possible to formulate pigmented protective coatings which will have improved adhesion to the coated materials by the use of the thermal-coefficient formula. The thermal-coefficient method described in this paper offers a rapid and reliable means of obtaining the basic physical data needed for use in the calculations. With such information the proper combination of materials can be calculated to yield a film matching the base material with respect to coefficient of thermal expansion.

Washington, June 18, 1946. 